\title{
Variasi Bahasa Tukul Arwana di Acara Bukan Empat Mata Trans 7 Dikaji dari Teori Etnografi Komunikasi Dell Hymes
}

\author{
Sigit Marteja \\ Guru SMA Negeri 1 Rejang Lebong Provinsi Bengkulu.
}

\begin{abstract}
Analyzed from Dells Hymmes's ethnographic communication theory. This research uses descriptive qualitative methodology. Consists of eight speech acts: a. arrangement b. participant c. ends d. act e. key f. instrument g. norm h. Genre. Basically, all research data are taken from the program "Not Four Eyes" in Jakarta Trans 7. The data comes from Tukul Arwana's speech acts. Data analysis was performed in series as follows: Codification, data editor, data presentation and inference. The results showed that the variation of Tukul Arwana language has special characteristics (Indiocretic), which means it has directive, expressive, contextual, contact, Meta linguistic, and poetic functions. The use of slanted material for students is the ability of class XI students to respond to television programs.
\end{abstract}

Keywords: Language variants, Dell Hymes communication ethnographic theory

\begin{abstract}
Abstrak
Dianalisis dari teori etnografi komunikasi Dells Hymmes. Penelitian ini menggunakan metodologi deskriptif kualitatif. Terdiri dari delapan tindak tutur: a. pengaturan b. peserta $\mathrm{c}$. berakhir d. bertindak e. kunci f. instrumen g. norma h. aliran. Pada dasarnya, semua data penelitian diambil dari program "Bukan Empat Mata" di Jakarta Trans 7. Data tersebut berasal dari tindak tutur Tukul Arwana. Analisis data dilakukan secara seri sebagai berikut: Kodifikasi, redaksi data, penyajian data dan inferensi. Hasil penelitian menunjukkan bahwa variasi bahasa Tukul Arwana memiliki karakteristik khusus (Indiosenkretik), yang berarti memiliki fungsi direktif, ekspresif, kontekstual, kontak, Meta linguistik, dan puitis. Penggunaan bahan miring untuk siswa adalah kemampuan siswa kelas XI untuk merespons program televisi.
\end{abstract}

Kata kunci: Varian bahasa, teori etnografi komunikasi Dell Hymes

\section{PENDAHULUAN}

Dalam setiap komunikasi manusia saling menyampaikan informasi dengan menggunakan alatnya berupa bahasa. Montgomery dalam Neil Thompson (2003,37) berpendapat Language indeed is best understood as set of interlocking relationships in which a linguistic form takes on the meaning it does by virtue of its place within the total system sign. Bahasa untuk menyambungkan hubungan komunikasi agar suatu maksud dapat dipahami . 
Penggunaan bahasa sebagai alat komunikasi yang dimiliki manusia mempunyai variasi atau ragam bahasa. Dell Hymmes dalam Abdul Chaer dan Leaonie Agustina (2004:48) menyatakan suatu peristiwa tutur harus memenuhi 8 komponen yakni latar(Setting), Participan ( Partisipant),Tujuan( Ends), Tindakan (Act), Cara (Key), Kode/Jalur (Instrumentalities), Norma (Norms), Ragam/Laras (Genre), jika digabung komponen tersebut berupa akronim "S.P.E.A.K.I.N.G".

Salah satu peristiwa tutur terjadi di acara televisi Bukan Empat Mata . sebuah acara bincang-bincang( talk show) di televisi swasta Trans 7 yang dibawakan oleh Tukul Arwana , acara ini mulai dipandunya sejak Juni 2006. Setiap acaranya menyampaikan tema tertentu yang diselingi dengan humor.

Presenter yang dikenal mempunyai nama "ndeso" Tukul Riyanto, lahir di Perbalan, Purwosari, Semarang, 16 Oktober 1963 adalah seorang pelawak dan pembawa acara. Selain menjadi pelaku hiburan, Ia juga merintis usaha yang bergerak di bidang hiburan, yang bernama "Ojo Lali Entertainment".

Penggunaan bahasa Kembaliiii...ke..lap toppp. Yang diucapkan presenter Tukul Arwana adalah jargon acara Bukan Empat Mata yang di tayangkan di televisi Trans 7 setiap Senin sampai Jumat pukul 22.00 sampai dengan 24.00. dan balik maning nang laptop karena dalam acara tersebut ia menggunakan laptop. Kemudian puas, puas, ,silent pleeeze, kerja, kerja, kerja, Susi Similikiti.

Berkaitan dengan pilihan suatu acara pemirsa televisi, peringkatan Rating merupakan ukuran tinggi-rendahnya pemirsa suatu acara di televisi. Semakin tinggi rating, semakin banyak pemasang iklan. harga jual slot siaran niaga pun semakin mahal. Ini berarti semakin besar pemasukan. Sebaliknya, jika ratingnya terus-menerus rendah, dapat dipastikan sebuah stasiun televisi takkan bisa bertahan.

Sisi positif yang penulis cermati yakni kepandaian presenter Tukul Arwana dalam memandu acara tersebut sehingga seluruh penonton di studio maupun di rumah tertawa . terutama penggunaan jargon bahasa yang diucapkannya .

Kompetensi Tukul Arwana dalam acara Bukan Empat Mata tersebut dapat menumbuhkan motivasi agar siswa mempelajari ketrampilan berbahasa dan peran (acting) sehingga menjadi presenter yang sukses.

Selanjutnya,peran pemerintah agar siaran televisi di Indonesia berdampak positif bagi masyarakat, di berlakukan Undang- Undang Penyiaran no:32 Tahun 2002 , di pasal 36 berbunyi :

Isi siaran wajib mengandung informasi ,pendidikan,hiburan dan manfaaat untuk pembentukan intelektualitas, watak,moral,kemajuan ,kekuatan bangsa,menjaga persatuan dan kesatuan,serta mengamalkan nilai-nilai agama dan budaya bangsa Indonesia.

Berdasarkan latar belakang tersebut, penelitian ini mengangkat judul Tesis variasi bahasa Tukul Arwana di acara Bukan Empat Mata Trans 7 dikaji dari Teori Etnografi Komunikasi Dell Hymes. 


\section{RUMUSAN MASALAH}

Berdasarkan latar belakang tersebut, rumusan masalah penelitian ini adalah sebagai berikut:

1. Bagaimanakah variasi bahasa TA di acara BEM Trans 7 di lihat dari sisi latar (Setting ) Teori Etnografi Komunikasi Dell Hymmes ?

2. Bagaimanakah variasi bahasa TA di acara BEM di lihat dari sisi partisipan( Participant) Teori Etnografi Komunikasi Dell Hymmes ?

3. Bagaimanakah variasi bahasa TA di acara BEM Trans 7 di lihat dari sisi tujuan (Ends) Teori Etnografi Komunikasi Dell Hymmes?

4. Bagaimanakah variasi bahasa TA di acara BEM Trans 7 di lihat dari sisi tindakan (Act) Teori Etnografi Komunikasi Dell Hymmes?

5. Bagaimanakah variasi bahasa TA di acara BEM Trans7 di lihat dari sisi cara (Key) Teori Etnografi Komunikasi Dell Hymmes ?

6. Bagaimanakah variasi bahasaTA di acara BEM Trans 7 di lihat dari sisi alat,stilistik (Instrument) Teori Etnografi Komunikasi Dell Hymmes ?

7. Bagaimanakah variasi bahasa TA di acara BEM Trans 7 di lihat dari sisi norma (Norms) Teori Etnografi Komunikasi Dell Hymmes?

8. Bagaimanakah variasi bahasa TA di acara BEM Trans 7 di lihat dari sisi tipe tuturan( Genre) Teori Etnografi Komunikasi Dell Hymmes

\section{TUJUAN PENELITIAN}

Berdasarkan rumusan permasalahan diatas, tujuan penelitian ini adalah sebagai berikut:

1. Untuk mengetahui variasi bahasa TA di acara BEM Trans 7 di lihat dari sisi latar (Setting) Teori Etnografi Komunikasi Dell Hymmes

2. Untuk mengetahui variasi bahasa TA di acara BEM Trans 7 di lihat dari sisi partisipan (Participant) Teori Etnografi Komunikasi Dell Hymmes

3. Untuk mengetahui variasi bahasa TA di acara BEM Trans 7 di lihat dari sisi tujuan(Ends) Teori Etnografi Komunikasi Dell Hymmes ?

4. Untuk mengetahui variasi bahasa TA di acara BEM Trans 7 di lihat dari sisi tindakan (Act) Teori Etnografi Komunikasi Dell Hymmes ?

5. Untuk mengetahui variasi bahasa TA di acara BEM Trans 7 dilihat dari sisi cara (Key)Teori Etnografi Komunikasi Dell Hymmes?

6. Untuk mengetahui variasi bahasa TA di acara BEM Trans 7 di lihat dari sisi alat,stilistik (Instrument) Teori Etnografi Komunikasi Dell Hymmes ?

7. Untuk mengetahui variasi bahasa TA di acara BEM Trans 7 di lihat dari sisi norma ( Norms) Teori Etnografi Komunikasi Dell Hymmes?

8. Untuk mengetahui variasi bahasa TA di acara BEM Trans 7 di lihat dari sisi tipe tuturan (Genre) Teori Etnografi Komunikasi Dell Hymmes? 


\section{MANFAAT PENELITIAN}

Penelitian ini menghasilkan seperangkat kajian terhadap variasi bahasa TA yang digunakan dalam acara BEM Trans 7 Jakarta. Hasil kajian tersebut dapat dimanfaatkan dalam berbagai hal yang berkaitan dengan fungsi komunikasi ; direktif, persuasi, puitik, kontekstual dapat juga dijadikan bahan ajar respon siaran televisi di kelas XI SMA.

Penelitian mengungkap bahasa yang digunakan dalam acara BEM untuk menghibur serta menginformasikan pirsawan televisi. Kegunaan penelitian ; bagi pembuat dan perancang program dapat memilih dan mengembangkan program berkualitas dan bertanggung jawab. Bagi pirsawan BEM dapat mengkaji secara bijak tontonan acara BEM . Bagi pendidik; penelitian berguna menambah wawasan kebahasaan kemudian dapat dijadikan bahan ajar di kegiatan pembelajaran. Bagi Peneliti lanjutan;penelitian dapat memberikan perspektif baru dalam kajian penelitian bahasa.

\section{ACUAN TEORITIK}

Pada bab ini membahas beberapa topik hasil kajian pustaka yang berkenaan dengan variasi bahasa, Etnografi Komunikasi Dell Hymmes, language gesture, language and interaction, communication and language, diksi dan gaya bahasa, paralinguistik, analisis interaksi, profil Tukul Arwana, acara talk Show Bukan Empat Mata, profil perusahaan TV Trans 7.

\section{Model Komunikasi}

Model komunikasi paling sederhana menurut pendapat sahnnon dan Veaver dalam Neil Thompson bahwa komunikasi terdiri transmiter,receiver dan noise. Transmiter orang / pihak yang menuturkan / menyampaikan pesan, receiver adalah orang / pihak yang menerima pesan, noise adalah faktor yang mempengaruhi komunikasi seperti emosi, atau masalah teknik seperti kualitas jaringan telepon. Model komunikasi di gambarkan sebagai berikut:

2. Variasi Bahasa

Bahasa mempunyai sistem dan subsistem yang dipahami sama oleh semua penutur bahasa itu, namun karena penutur bahasa tersebut tidak berada di masyarakat yang homogen, maka wujud bahasa yang konkret ,yang disebut parole menjadi tidak seragam, bahasa itu menjadi beragam dan bervariasi (Chaer,2004:61).

Variasi atau ragam bahasa merupakan bahasan pokok dalam studi sosiolinguistik, Kridalaksana dalam Abdul Chaer mendifinisikan sosiolinguistik sebagai cabang linguistik yang berusaha menjelaskan ciri-ciri variasi bahasa dan menetapkan korelasi ciri-ciri variasi bahasa tersebut dengan ciri-ciri sosial kemasyarakatan (Chaer ,2004:61). 
John J Gumperz menyatakan

" interactional sosiolinguistic is general term used to describe a number of qualitative approaches to the analysis of interactive and dialogic processes in interpersonal communication. Its root lie in the fields of sosiology,anthropology and linguistic,as reflected by interactional sosiolinguistic, interest in the closely knit interplay existing between language,society and culture, and in the “communicative import of diversity". (2002:85)

Dari pendapat-pendapat tersebut disimpulkan bahwa sosiolinguistik adalah menganalisis proses dialog komunikasi yang berada di bidang sosiologi, anthropologi dan linguistik .

Jenis-jenis variasi bahasa berdasarkan penuturnya menurut Abdul Chaer sebagai berikut:

(1) Idialek adalah variasi bahasa yang bersifat perseorangan,setiap orang mempunyai variasi bahasanya masing-masing,(2)Dialek adalah variasi bahasa dari sekelompok penutur yang jumlahnya relatif,yang berada pada suatu tempat,wilayah atau area tertentu,(3) Kronolek adalah variasi bahasa yang digunakan oleh kelompok sosial pada masa tertentu,misalnya variasi bahasa tahun limapuluhan,(4) Sosialek adalah variasi bahasa yang berkenaan status ,golongan,dan kelas sosial para penuturnya (2004:61-64)

Variasi bahasa berdasarkan pemakaian bahasa disebut ragam bahasa. Jumlahnya dalam bahasa indonesia tidak terbatas. Oleh sebab itu ,ragam bahasa dibagi atas dasar pokok pembicaraan, medium pembicaraan dan hubungan antar pembicara.

\section{Etnografi komunikasi Dell Hymmes}

Kajian sosiolinguistik yang tergolong mendapat perhatian cukup besar adalah kajian tentang etnografi komunikasi. Etnografi adalah kajian tentang kehidupan dan kebudayaan suatu masyarakat atau etnik, misalnya tentang adatistiadat, kebiasaan, hukum, seni, religi, bahasa. Bidang kajian vang sangat berdekatan dengan etnografi adalah etnologi, yaitu kajian perbandingan tentang kebudayaan dari berbagai masyarakat atau kelompok (Richards, dalam Purwoko 2008:8).

Semula etnografi komunikasi (etnography of communication ) disebut etnografi wicara atau etnografi pertuturan ( ethnograpliy of speaking). Kalau etnografi itu dipandang sebagai kajian yang memerikan suatu masyarakat atau etnik, model pemerian etnografi itu bisa diterapkan dan difokuskan kepada bahasa masyarakat atau kelompok masyarakat tertentu. Karena sosiolinguistik itu lebih banyak mengungkapkan pemakaian bahasa, dan bukan ihwal struktur bahasa, maka etnografi tentang bahasa difokuskan kepada pemakaian bahasa dalam pertuturan atau lebih luas lagi komunikasi yang menggunakan bahasa. 
Dell Hymes dalam Alex Sobur (2009:155 ) memprihatinkan karya para pakar antropologi dan linguistik yang melupakan wilayah komunikasi manusia yang luas dan penting. Para antropolog telah lama melakukan kajian etnografis tentang aspek-aspek budaya seperti sistem kekerabatan, pandangan tradisional tentang obat-obatan dan penyembuhan penyakit; persoalan bahasa diperlakukan di bawah aspek lain, yaitu. sebagai sarana untuk memperoleh topik-topik lain dari bahasa. Banyak buku yang megkaji tentang perbandingan agama, perbandingan politik, dan sebagainya, tetapi tidak ada buku tentang perbandingan wicara dari berbagai suku. Para linguis, menurutnya juga terlalu mementingkan bahasa sebagai sistem abstrak. Mereka terpaku untuk memerikan dan menjelaskan struktur kalimat yang dianggap gramatikal oleh penutur asli. Namun, bagaimana orang menggunakan kalimat itu apakah berbeda dengan kalimat lain, apakah kalimat itu menyuruh orang lain, atau memamerkan ujaran saja, dianggap di luar perhatian teori linguistik.

Pendapat Dell Hymes dalam Abdul Syukur Ibrahim(2009:148) “para pakar ilmu sosial memisahkan diri dari isi tutur, dan kedua pakar itu memisahkan diri dari pola penggunaan tutur". Etnografi komunikasi akan mengisi kesenjangan itu dengan menambahkan hal lain (pertuturan atau komunikasi) terhadap topiktopik garapan bidang antropologi bagi pemerian etnografis, dan mengembangkan kajian linguistik. Linguistik yang lebih lengkap akan dikaitkan bagaimana penutur menggunakan struktur tersebut.

\section{METODOLOGI PENELITIAN}

Pada bagian ini dibahas topik-topik yang berkenaan dengan metode penelitian yang dilakukan.

Secara berurutan disajikan pendekatan penelitian,sumber data, teknik pengumpulan data, analisis data, triangulasi data dan temuan dan posisi peneliti dalam penelitian

\section{Pendekatan Penelitian}

Pendekatan penelitian ini menggunakan pendekatan deskriptif kualitatif. Penggunaan pendekatan ini dilandasi oleh pertimbangan bahwa pendekatan deskriptif memiliki karakteristik yang sesuai untuk melaksanakan penelitian ini. Pendekatan deskriptif kualitatif dapat digunakan untuk memaparkan situasi atau peristiwa, tidak mencari atau menjelaskan hubungan, tidak menguji hipotesis atau membuat prediksi ( Hariwijaya,2007:48),

Berdasarkan pendapat Hariwijaya (2007:49) bahwa pendekatan deskriptif kualitatif ini bertujuan untuk (1) mengumpulkan informasi aktual secara rinci, (2) mengidentifikasi masalah atau memeriksa kondisi dan praktik-praktik yang berlaku,(3) membuat perbandingan evaluasi ,(4) menentukan apa yang dilakukan orang lain dalam menghadapi masalah yang sama dan belajar dari 
pengalaman mereka untuk menetapkan rencana dan keputusan pada waktu yang akan datang.

Selanjutnya, pendekatan deskriptif berguna untuk melahirkan teori-teori tentatif., bukan menguji teori hypotesis generating, bukan hypotesis testing dan heuristic bukan verikatif (Hariwijaya,2007:49). Berikutnya pendapat Borg and Galll dalam Sugiyono (2009:213) menyatakan bahwa:

"Qualitatif research is much more difficult to do well than quantitatif research because the data collected are usually subjective and the main measurement tool for collecting data is the investigator himself ". Penelitian kualitatif lebih sulit bila dibandingkan dengan penelitian kuantitatif, karena data yang dikumpulan bersifat subjektif dan instrumen sebagai alat pengumpul data adalah peneliti itu sendiri.

Penelitian kualitaif deskriptif yang digunakan bersifat induktif, teori yang dikembangkan dimulai dari transkip TA di acara BEM, dari transkip tersebut kemudian akan di kaitkan dengan teori Hymmes; Setting, Participant, End, Act, Keys,Norm, Genre (S.P.E.A.K.I.N.G) prosedur yang dilakukan tersebut dinamakan bootom up grounded research (Sugiyono, 2009: 214).

\section{Sumber Data Penelitian}

Yang dimaksud sumber data penelitian adalah data yang diperoleh langsung dari lapangan termasuk laboratorium ( Nasution,2008:143). Dalam penelitian ini, data penelitian berupa data ujaran dari peristiwa tutur yang terjadi pada acara BEM yang dipandu TA di Trans 7.

Data ujaran tersebut diperoleh dari transkipsi acara BEM yang diucapkan Presenter TA. berhubung lamanya acara BEM, peneliti hanya akan menggunakan data penelitian 5 bintang tamu Happy Salma,Rita Sugiarto,Alice Norin,Pongky dan Sofi, Yuanita.

Alasan 5 bintang tamu dalam penelitian ini, karena dalam 1 minggu acara BEM ditayangan 5 episode, masing-masing episode diundang tiga sampai empat bintang tamu. menurut peneliti 5 bintang tamu,sudah cukup terwakili data penelitian.

\section{Metode Penyediaan Data}

Menurut Mahsun(2005:242) Metode yang dapat digunakan dalam tahap penyediaan data untuk penelitian sosiolinguistik, sebenarnya dapat memanfaatkan jenis-jenis metode yang digunakan dalam penelitian sosial, namun, pada prinsipnya ,setidak-tidaknya ada tiga metode yang dapat digunakan, yaitu metode observasi (simak /pengamatan), survei dan cakap/wawancara.

Berdasarkan pendapat tersebut, metode penyediaan data di penelitian ini dipergunakan metode observasi ( simak / pengamatan) dengan pertimbangan, 
bahwa data sudah jelas di acara BEM yang di tayangkan Trans 7 dan tidak melibatkan responden.

Metode observasi merupakan metode yang digunakan dalam penyediaan data dengan cara di lakukan observasi variasi penggunaan bahasa TA yang ditayangkan televisi Trans 7 pada bulan April 2010. Teknik ini digunakan dengan pertimbangan, bahwa perilaku berbahasa hanya dapat dipahami jika peristiwa berbahasa itu berlangsung dalam situasi sebenarnya yang berada dalam konteks yang lengkap.

\section{Prosedur Pengumpulan Data Penelitian}

Observasi atau pengamatan merupakan suatu teknik atau cara mengumpulkan data dengan jalan pengamatan terhadap kegiatan yang berlangsung (Nasution,2008:106)

Teknik observasi di penelitian ini diadakan perekaman elektronik dan pencatatan terhadap data ujaran yang ditraskripsikan . Perekaman elektronik dilakukan dengan perangkat TV Tunner merk MSI yang dilengkapi dengan PC komputer yang dihubungkan dengan pesawat televisi ,dilakukan pengeditan pemisahan antara iklan dengan acara BEM dengan software pinnacle 9 plus.

5. Analisis Data

Analisis data menurut Mahsun adalah upaya yang dilakukan untuk mengklasifikasikan ,mengelompokkan data. Pada tahap ini dilakukan upaya pengelompokkan ,menyamakan data yang sama dan membedakan data yang memang berbeda, serta menyisihkan pada kelompok lain data yang serupa, tetapi tidak sama (2005:253).

Analisis data dilakukan sejak awal pengumpulan data sampai semua data telah terkumpul. Di penelitian ini, ada tiga tahapan pokok dalam analisis data, yakni;

(1) tahap kodifikasi dan reduksi data

Pada tahap kodifikasi dan reduksi ada beberapa kegiatan seperti proses pemilihan, proses identifikasi,pemberian kode ( sesuai dengan butir-butir masalah yang diteliti) pada korpus data,dan proses pengorganisasian. Selanjutnya, berdasarkan pengkodean dan pengorganisasian dilakukan reduksi data untuk mendapatkan indikator-indikator yang signifikan untuk setiap aspek masalah yang diteliti. Untuk data yang tidak mencerminkan indikator yang signifikan reduksi atau tidak diikutkan dalam analisis selanjutnya. Dengan demikian diperoleh kelompok data yang layak dan representatif. Hasil reduksi data ini secara keseluruhan disajikan dalam bentuk tabel-tabel menggunakan kolom No percakapan,no data, data yang sudah diidentifikasi dan koding, keterangan.

(2) tahap analisis

Sesuai dengan karakteristik penelitian kualitatif menurut Mahsun(2005:260) bahwa dalam kegiatan analisis data terdapat kegiatan proses 
sintesis, pencarian pola-pola,penemuan makna, dan penentuan bagian-bagian yang perlu dilaporkan.

Dalam penelitian ini tahap analisis data menggunakan indikator S-P-E-AK-I-N-G (setting, participant, ends, act, key, instrumentalities, norms, genre).

\section{Posisi Peneliti}

Dalam penelitian ini, posisi peneliti sebagai subyek yang tidak bebas nilai dan netral. Peneliti akui sebagai subyek yang mempunyai pandangan nilai dan keyakinan tertentu. Semuanya itu akan mempengaruhi hasil penelitian.

Kedudukan peneliti juga sebagai penerima, oleh sebab itu, peneliti perlu memhami kode bahasa yang digunakan TA sehingga dapat memecahkan kode pesan yang disampaikan oleh pengirim di acara BEM. Bagi peneliti sebagai penerima, Hasil penafsiran pesan TA sangat tergantung pemahaman .

\section{HASIL PENELITIAN DAN PEMBAHASAN}

Dibawah ini dibahas variasi bahasa TA di acara BEM Trans 7 di kaji dari teori Etnografi Komunikasi . dengan batasan masalah kajian dari kisi S-P-E-A-K-I-N-G Dell Hymmes. hasil penelitian didasarkan pada atas rumusan masalah penelitian. Pada bagian ini dibahas

(a) variasi bahasa TA di acara BEM Trans 7 di lihat dari sisi Setting (latar) Teori Etnografi Komunikasi Dell Hymmes (b) variasi bahasa TA di acara BEM Trans 7 di lihat dari sisi partisipan ( Participant) Teori Etnografi Komunikasi Dell Hymmes (c) variasi bahasa TA di acara BEM Trans 7 di lihat dari sisi tujuan (Ends) Teori Etnografi Komunikasi Dell Hymmes (d) variasi bahasa TA di acara BEM Trans 7 di lihat dari sisi tindakan (Act) Teori Etnografi Komunikasi Dell Hymmes (e) variasi bahasa TA di acara BEM Trans 7 di lihat dari sisi cara (Key) Teori Etnografi Komunikasi Dell Hymmes (f) variasi bahasa TA di acara BEM Trans 7 di lihat dari sisi alat,stilistik (Instrument) Teori Etnografi Komunikasi Dell Hymmes (g) variasi bahasa TA di acara BEM Trans 7 di lihat dari sisi norma (Norms) Teori Etnografi Komunikasi Dell Hymmes (h) variasi bahasa TA di acara BEM Trans 7 di lihat dari sisi tipe tuturan( Genre) Teori Etnografi Komunikasi Dell Hymmes .

Penjelasan secara rinci tentang hasil penelitian dan pembahasan dapat dibaca pada uraian berikut ini.

\section{HASIL PENELITIAN}

Dibagian ini akan di paparkan hasil penelitian tentang variasi bahasa TA di acara BEM , sumber data sebanyak 5 bintang tamu di 5 episode yang ditayangkan pada bulan april 2010: 


\section{A.1.variasi bahasa TA dalam acara BEM dilihat dari sisi latar(setting)}

Di dalam sebuah ruangan;sebuah ruangan yang ada penonton, pembawa acara, grup musik,lampu spotlight, kamera ,krew dan perlengkapan berupa sofa warna merah, televisi, gambar perkotaan di waktu malam/ lampu warna-warni.

Di tengah-tengah panggung terletak seperangkat kursi tamu berwarna merah dan gambar latar ( background) kota metropolitan di waktu malam, di sebelah kiri di letakkan seperangkat alat band dan disebelah kanan di letakkan seperangkat perabot kedai sederhana ( mini bar). Di depan panggung dan di balkon adalah tempat duduk penonton .di belakang kursi terletak pendingin udara( air conditioner) berwarna putih metalik dan sebuah televisi Liquid Cystal Display berwarna hitam, didalam televisi itu di tampilkan judul mata acara peristiwa tutur TA yaitu BEM.

Pada acara BEM berlangsung tuturan TA seringkali menggunakan latar (setting) acara kata BEM sebagai pembuka, saat akan jeda iklan serta saat setelah jeda iklan..Untuk lebih jelasnya dapat dilihat pada contoh dibawah ini:

\section{$\operatorname{Contoh}(1)$}

no data: 1

TA : Oke, ketemu lagi, dibukan empat...mata!( TA mengacungkan kedua jarinya ke arah audien)

\section{Konteks:}

Peristiwa tutur tersebut terjadi setiap membuka acara BEM di Trans 7 Jakarta.

Pada contoh diatas dapat kita lihat salah satu tuturan TA yang mengandung komponen tutur seting yaitu BEM. Pada saat membuka acara BEM . Kemudian contoh tuturan TA pada saat akan jeda iklan dan setelah jeda iklan dtunjukkan dibawah ini:

\section{Contoh(2)}

no data: 88

TA :oke, masih di bukan empat mata! (posisi duduk, kemudian TA mengacungkan menngunakan jari telunjuk dan tengahnya.

Konteks:

Peristiwa tutur tersebut terjadi pada saat akan jeda iklan dan setelah jeda iklan.

Pada penelitian 5 bintang tamu, kata BEM di sebut 5 kali saat pembukaaan, 5 kali saat akan jeda iklan serta 5 kali setelah jeda iklan.

Berkaitan dengan bahasa non verbal ,saat di tuturkan "oke,masih di bukan empat mata" tangan TA menunjuk hal yang tidak lazim yaitu dengan menggunakan jari 
telunjuk dan jari tengahnya .gerakan tangan tersebut tidak diketemukan pada presenter lain ,dengan demikian gerakan ini merupakan gaya khas TA di acara BEM. Agar lebih jelas dapat dilihat di figur TA 1 , figur TA 2.serta figur TA 20.

\section{A.2.variasi bahasa TA dalam acara BEM dilihat dari sisi partisipan}

Pada acara BEM berlangsung tuturan TA seringkali melibatkan mitra tutur Chintia Sari ,bintang tamu,penonton, pemusik ,krew acara serta pada saat kuis melibatkan pirsawan di rumah.

Pada saat pembukaan acara BEM, partisipan sering di sapa TA dengan beberapa tuturan. Untuk lebih jelasnya dapat dilihat pada contoh dibawah ini:

Contoh (3)

No data:2

TA : oo,gitu,kamu harus lebih meriah dari pada diatas(TA menunjuk penonton yang berada di balkon)

Konteks:

Peristiwa tutur tersebut terjadi pada awal acara BEM, TA meminta penonton yang didepan ikut bersorak dan tertawa lebih meriah.

Pada contoh tuturan diatas TA menggunakan variasi bahasa "oo,gitu,kamu..." memberikan kesan "akrab "dan" intim" pada partisipan .contoh lain, ditunjukkan dibawah ini:

Contoh (4):

No data: 8

TA : hey ,apa kabar,mantan majikan saya,Happy Salma(TA duduk di sofa merah dihadapan HS )

HS : baik juga,mantan pelatih anjingku dirumah

Konteks:

Peristiwa tutur tersebut terjadi pada acara BEM tanggal 7 april 2010, Happy Salma di undang sebagai bintang tamu.

Pada contoh tuturan tersebut tercipta komunikatif representasional "humor" membuka komunikasi lebih terjalin dengan baik.Kata'majikan" yang di ujarkan oleh TA tidak memberi makna yang sebenarnya( denotatif) hanya sekedar membuat "tertawa" partisipan lain. begitu juga, kata" pelatih ajingku" hanya memberikan "asal jawaban".

Contoh berikutnya, tuturan TA kepada bintang tamu Rita Sugiarto, .untuk lebih jelasnya dapat dilihat pada contoh dibawah ini:

Contoh (5) : 
no data :59

TA : Dia adalah salah satu penyanyi senior dangdut , mau tahu gimana nostalgia dia,diawal karier, mari kita sambut Rita Sugiarto(kemudian Rita Sugiarto muncul dari pintu panggung ,berjalan kearah tengah panggung disertai bunyi musik )

Konteks:

Peristiwa tutur tersebut terjadi pada acara BEM ,bintang tamu Rita Sugiarto

Pada contoh diatas dapat dilihat TA menggunakan variasi bahasa fungsi komunikasi deklaratif memberikan pernyataan"siapa mitra tutur yang akan dihadirkan" didalam kalimat itu di informasikan juga bagaimana awal karier dan nostalgia Rita Sugiarto (partisipan). Selanjutnya, RS setelah dipersilahkan ke panggung oleh TA, dia menyanyikan sebuah lagu dangdut. Cara tampil RS(partisipan) tersebut memeriahkan acara BEM.

Peranan pasangan (Partner) TA yakni Chintia Sari sebagai mitra tutur di acara BEM mempunyai peranan pemarkah TA .Untuk lebih jelasnya dapat dilihat pada contoh dibawah ini:

Contoh(6):

no data $: 78$

CS :kita kangen nyayikan lagi,mbak !(meminta Rita Sugiarto menyayikan kelanjutan sebuah lagu dangdut)

RS :(menyanyikan sebuah lagu)

TA : :saya senang lagu, itu. Luar biasa. Monggo, mbak duduk !(TA mempersilahkan duduk RS)

konteks:

Peristiwa tutur tersebut terjadi di acara BEM ,pada saat menghadirkan bintang tamu;Rita Sugiarto.mereka (TA,RS,CS) duduk di sofa berwarna merah .

Pada contoh diatas dapat kita lihat salah satu variaisi bahasa TA yang di "pancing" oleh CS..

\section{A.3.variasi bahasa TA dalam acara BEM dilihat dari sisi tujuan(ends)}

Pertanyaan - pertanyaan yang ditujukan ke bintang tamu biasanya sudah ditulis didalam lap top serta mengacu pada topik yang diangkat.Pada penelitian selama 5 episode ,variasi bahasa TA hanya membumbuhi pertanyaan -pertanyaan yang berasal dari lap top.Untuk lebih jelasnya dapat dilihat pada contoh dibawah ini: 
Contoh (7) :

Topik: april mop

No data:26

TA :Happy Salma yang,ehem..talk about keisengan yang dilakukan tanggal 1 april, gimana nih, april mop tahun ini,sudah ngerjain siapa,atau malah sudah dikerjain siapa,nih,monggo

Konteks:

Peristiwa tutur tersebut terjadi pada bulan april 2010 di acara BEM dengan topik april mop. Bintang tamu yang hadir;Happy Salma,Afgan,Intan nuraini

Pada contoh tuturan diatas TA menggunakan variasi bahasa fungsi komunikatif interrogative,yaitu menanyakan keisengan apa sajakah yang telah dilakukan bintang Tamu( Happy Salma) berkenaan dengan peristiwa april mop.

Kemudian di episode berikutnya mengangkat topik too sweet too forget (terlalu indah untuk dilupakan). Untuk lebih jelasnya dapat dilihat pada contoh dibawah ini:

Contoh (8) :

Topik : too sweet to forget

No data: 89

TA :Talk about nostalgia ternyata dulunya,mbak Rita Sugiarto penyanyi ,pop,ya?

Konteks:

Peristiwa tutur tersebut terjadi di acara BEM mengankat topik too sweet too forget.

Pada contoh tuturan tersebut tercipta komunikatif interrogative yakni ingin mengetahui apakah Rita Sugiarto sebelum menjadi penyanyi dangdut, adalah seorang penyanyi pop.

\section{A.4.variasi bahasa TA dalam acara BEM dilihat dari sisi urutan tindak(act)}

Pada awal acara BEM berlangsung.TA berusaha menarik perhatian penonton atau partisipan,oleh karena itu, pada saat masuk panggung, TA seringkali berjoged lebih dahulu.setelah itu, dia berdiri ditengah-tengah panggung dengan penuh senyum ,menyapa seluruh Audien dan pirsawan .Untuk lebih jelasnya dapat dilihat pada contoh dibawah ini:

Contoh (9) :

No data:144.a

TA : Penontonnya bagus( tangan TA mengangkat kedua ibu jarinya ke arah penonton) 
Konteks:

Peristiwa tutur tersebut terjadi pada acara BEM . TA mengangkat kedua ibu jari kearah audien.

Pada contoh diatas,dapat kita lihat variasi bahasa TA mempunyai fungsi komunikasi ekspresif yaitu memuji atas kehadiran di acara BEM.

Penggunaan kinisic berupa gestur yang dilakukan TA dapat digambarkan seperti

figur Tukul 2.

Contoh berikutnya ditunjukkan di bawah ini:

Contoh (10) :

No data:7.a

TA : Kembali ke lap ..top( tangan menunjuk ke arah audien dengan jari telunjuk dan jari tengah)

Konteks:

Peristiwa tutur tersebut terjadi pada saat TA ingin memberikan pertanyaan berikutnya .

Pada contoh diatas dapat kita lihat tindak tutur yang dilakukan TA melibatkan partisipan secara langsung karena audien akan merespon kalimat kembali ke lap top dengan mengatakan "toop" disertai menunjuk ke arah TA. Penggunaan kinisic berupa gestur yang dilakukan TA dapat digambarkan di figur Tukul 9.

A.5.variasi bahasa TA dalam acara BEM dilihat dari sisi cara/kunci (key)

Pada acara BEM berlanghsung. Variaisi bahasa TA disampaikan dalam suasana santai dan lucu ,hal tersebut ditunjukkan saat TA berbicara atau bertingkah laku kemudian audien tertawa,bersorak serta bertepuk tangan. Untuk lebih jelasnya dapat dilihat pada contoh dibawah ini:

\section{Contoh(11)}

No data:57

TA :Pemirsa bintang tamu saya yang pertama adalah seorang wanita cantik yang mempunyai suara tinggi 19 oktaf.(berdiri,tangan sebelah kanan menunjuk ke atas)

CS : Marieh carey saja,9 oktaf

Konteks: 
Peristiwa tutur tersebut terjadi pada acara BEM bintang tamu Rita Sugiarto(penyanyi dangdut)

Pada contoh variasi tuturan diatas,dapat dilihat bahwa TA ingin "apa yang diucapkannya di tanggapi lucu".

Penggunaan kinisic ditunjukkan digambar figur tukul 10.

Contoh berikutnya, ditunjukkan dibawah ini:

Contoh(12)

No data:38

TA : duduk kok ,kayak kenduren,biasa saja !( melihat beberapa penonton yang duduk bersila)

Konteks:

Peristiwa tutur tersebut terjadi diawal acara BEM, ta memperhatikan beberapa penonton yang duduk bersila

Pada contoh diatas, tuturan bahasa tukul mempunyai kunci(key) "lucu" kemudian berubah menjadi "sinis". Selanjutnya,auidien merespon "apa yang dikatakan TA" menjadikan suasana yang santai dan lucu.

A.6.variasi bahasa TA dalam acara BEM dilihat dari sisi instrumen(instrumentalis)

Pada acara BEM berlangsung. Variasi bahasa TA menggunakan bahasa verbal (tuturan) maupun bahasa non verbal meliputi; proximics, cronemics, oculesics, haptic, obyectic, vocalic, kinesics.

Untuk lebih jelasnya dapat dilihat pada contoh dibawah ini:

Contoh (13):

No data:77

TA : first song...song first( jari tangan kananya direnggangkan kemudian di gosokkan sebanyak 2 kali di sandaran sofa/kursi)

Konteks:

Peristiwa tutur tersebut terjadi saat berdialog dengan Rita Sugiarto)

Pada contoh diatas dapat kita lihat salah satu variaisi bahasa TA pada saat menuturkan "first song", TA sengaja menuturkan yang kedua dibalik menjadi " song first",pembalikan tuturan ini disengaja oleh TA untuk menimbulkan kelucuan; "first song" tidak sama artinya dengan"song first"

Di penggunaan bahasa non verbal, gestur TA yang menggosok-gosok tangannya akan merespon audien dengan bersorak"ya...уа..уа..." dan tepuk tangan.Untuk lebih jelasnya,gestur TA digambarkan seperti di figur Tukul 18. 
Contoh berikutnya ditunjukkan dibawah ini:

Contoh(14):

No data: 125

TA : Monyong-monyong( maksudnya,ngomong-ngomong)

Konteks:

Peristiwa tutur tersebut terjadi pada acara BEM menghadirkan bintang tamu Alice Norin

Pada contoh diatas dapat kita lihat variasi bahasa TA menggunakan bentuk tuturan dialek jawa,walaupun TA bermaksud menuturkan"ngomong-ngomong" tapi di ubah"diplesetkan" menjadi kata"monyong-monyong". Dampak pengubahan tuturan tersebut,audien merespon dengan tertawa atau di interprestasikan lucu.

Penggunaan bahasa non verbal digambarkan di figur Tukul 25.posisi TA duduk menghadap bintang tamu dan ,kaki disilangkan.

A.7.variasi bahasa TA dalam acara BEM dilihat dari sisi norma(norms)

Pada awal acara BEM, TA selalu membuka ,menutup dan jeda iklan dengan suatu sikap yang khas yang tidak ditemukan pada presenter lain.Untuk lebih jelasnya dapat dilihat pada contoh dibawah ini:

Contoh (15):

No data:124.a

TA :Selamat malam Dj cantikku,apa kabar,you look so great!(duduk menghadap bintang tamu).

Konteks:

Peristiwa tutur tersebut terjadi pada BEM bintang tamu Alici Norin.

Pada contoh diatas dapat kita lihat salah satu bentuk variaisi bahasa yang digunakan TA dari sisi norma interprestasi: bersikap sopan kepada mitra tutur( Alice Norin), sapaan yang akrab dan bersahabat.

Contoh (16):

No data :124

TA :sebelumnya saya turut belasungkawa atas meninggalnya ayah,mas Pongky (duduk menghadap bintang tamu, mas Pongky dan Sofi)

Konteks:

Peristiwa tutur tersebut terjadi pada acara BEM bintang tamu;mas Pongky.

Pada contoh diatas dapat kita lihat salah satu bentuk variaisi bahasa fungsi komunikasi phatic,kepedulain TA atas meninggalnya orang tua mas Pongky. Tuturan ini memberikan norma interaksi yang santun kepada mitra tutur , memberikan keakraban.

A.8.variasi bahasa TA dalam acara BEM dilihat dari sisi tipe tuturan(genre) 
Acara talk show BEM yang disiarkan oleh stasiun televisi Trans 7 ini, merupakan acara hiburan yang menggunakan presenter seorang pelawak yaitu TA.oleh karena itu, tuturan yang di tuturkan oleh TA di lihat dari sisi tipe tuturan (genre) adalah tipe hiburan.Untuk lebih jelasnya dapat dilihat pada contoh berikut ini:

Contoh(17)

No data:69

TA :gimana ceritanya,mbak Rita bisa pindah aliran listrik ini,monggo !( duduk menghadap bintang tamu,Rita Sugiarto)

Konteks:

Peristiwa tutur ini terjadi pada acara BEM bintang tamu,Rita Sugiarto.

Pada contoh diatas dapat kita lihat variasi bahasa TA "aliran listrik" hanya untuk memberikan hiburan bagi pemirsa atau audien .sebenarnya yang dimaksud “aliran musik :"bukan aliran listrik.

Penggunaan bahasa non verbalnya dapat digambarkan pada figur Tukul 16. Posisi duduk di pinggir sofa menghadap bintang tamu ; mbak Rita Sugiarto.

\section{PEMBAHASAN}

Di bagian ini akan di paparkan pembahasan variasi bahasa TA dalam acara BEM bila dikaji dari kisi S-P-E-A-K-I-N-G teori etnografi komunikasi Dell Hymmes. komponen tutur setting, participant, ends, act, key, instrumental, norms dan genre.

1. Variasi bahasa TA di acara BEM Trans 7 di lihat dari sisi latar(setting ) Teori Etnografi Komunikasi Dell Hymmes

Latar (setting) peristiwa tutur berupa acara talk show BEM Trans 7 .Variasi bahasa TA yang dituturkan pada awal acara BEM menggandung fungsi komunikatif direktif . Kalimat pembuka selalu dituturkan TA"oke, ketemu lagi di bukan empat mata", diikuti gestur menunjuk dengan jari telunjuk dan jari tengah ke arah penonton.tidak diketemukan kalimat lain. Variasi bahasa TA pada saat akan jeda iklan, yaitu" jangan kemana-mana tetap dibukan empat mata" diikuti gestur menunjuk dengan jari telunjuk dan jari tengahnya ke arah penonton.mengandung fungsi direktif persuasif.. Variasi bahasa TA pada saat setelah jeda iklan, yaitu"oke,masih di bukan empat mata" diikuti gestur menunjuk dengan jari telunjuk dan jari tengahnya ke arah penonton.mengandung fungsi deklaratif.

Hymmes dalam Abdul Syukur(2009:158) katalog lengkap fungsi komunikasi di teori etnografi harus mengandung direktif, ekspresif, puitik, fungsi kontak, metalinguistik, representasional, serta kontekstual. 
Kenyataan variasi bahasa yang dipakai TA hanya memenuhi unsur direktif, ekspresif dan fungsi kontak sedangkan fungsi kontekstual, puitik representasional belum nampak.

2. Variasi bahasa TA di acara BEM Trans 7 di lihat dari sisi partisipan (participant) Teori Etnografi Komunikasi Dell Hymmes?

Partisipan dalam peristiwa tutur ini yaitu Chintia Sari (partner) A.Lomova, penonton, bintang tamu, krew tv, dan personil band pengiring serta pirsawan di rumah saat diadakan kuis.

Jenis variasi bahasa TA sebagai penutur adalah variasi bahasa bersifat perseorangan, banyaknya ragam tak terbatas, berkaitan dengan makna dibalik tutur TA , makna sosialnya TA berasal dari "ndeso" yang berlatar belakang orang jawa. nilai tutur komunikasinya sering menggunakan sisipan kalimat bahasa jawa ngoko.seperti "sak karepmu","krungu-krungu"

Paralinguistik yang sering digunakan TA seperti berdehem yang dilengkingkan suaranya, kemudian pada saat akan jeda iklan TA akan mengujarkan dengan tempo yang dipercepat pada kalimat" jangan kemanamana,tetap di bukan empat mata!"

Gesture TA mengandung makna pada saat duduk kaki disilangkan mengandung makna sikap acuh tak acuh, senyum mulut dibuka sedikit mengandung makna senyum simpul, senyum mulut dibuka lebar senyuman lebar, tangan sering di rentangkan mengandung makna karakter terbuka, menutup mulut dengan tangan saat bicara mengandung makna terheran-heran. tangan didada mengandung makna jujur. Gaya bertepuk tangan TA tidak ada di ketemukan di makna gesture, gerakan tersebut menjadikan ciri khas TA"idiosinkretik".

Dell Hymmes dalam J.D Parera(2004:236-237 selain katalog lengkap fungsi komunikasi di teori etnografi ,dalam interaksi dengan mitra tutur ada 2 jenis peranan yaitu event dan act. Peranan Chintia Sari seharusnya sebagai pemancing/pemarkah ternyata hanya sebagai penyela saja.bahkan, terkesan hanya menyudutkan TA .seharusnya Chintia Sari sebagai pemancing (act )dan TA berperan pelanjut (event),peranan krew musik sebagai partisipan sering hanya menjadi obyek ejekan (non phatic) oleh TA, sehingga variasi bahasa TA jika disimak tergolong kasar.Peranan penonton sebagai partisipan hanya memeriahkan peristiwa tutur saja,seperti tertawa,bersorak,merespon kata"kembali ke lap toop" dari TA.Kadang-kadang di puji (amelioratif) maupun direndahkan (peyoratif) .

Posisi tempat duduk partisipan di panggung dalam bentuk segitiga (triadic), dalam posisi ini, partisipan dapat melakukan interaksi dengan baik. 
sedangkan tempat duduk penonton membentuk $1 / 2$ lingkaran (diadic) ke arah panggung.

3. Variasi bahasa TA di acara BEM Trans 7 di lihat dari sisi tujuan (ends) Teori Etnografi Komunikasi Dell Hymmes .

Tujuan (ends) peristiwa tutur di informasikan di awal acara BEM kepada seluruh partisipan.tujuan mencakup maksud dan hasil yang akan dipilah atas tujuan dari acara BEM dipandang dari sudut budaya (outcomes) dan tujuan dari masing-masing partisipan.

Variasi bahasa TA berkaitan dengan tujuan (ends) di peristiwa tutur BEN sudah di arahkan melalui tampilan di lap top.jika dalam tuturan TA tidak sesuai dengan tujuan(ends) di episode itu, TA segera mengatakan"kembali ke lap top". Kalimat"kembali ke lap top" mempunyai fungsi komunikasi direktif persuasif.interprestasi dari kalimat tersebut berarti tindak tutur yang sedang berlangsung harus tetap relevan dari tujuan (ends) yang sedang di tuturkan.Kalimat"kembali ke lap top" berarti pengontrol ,tindak tutur yang sedang berlangsung.

Pendapat Hymmes dan H.P Grice (dalam, JD Parera, 2004:224), prinsip kooperatif terdiri 4 sub maksim yaitu: kualitas, kuantitas, relevan,cara.

Variasi bahasa TA "kembali ke lap top" sudah memenuhi 4 sub maksim ,yaitu submaksim kualitas mengandung maksud jujur artinya pertanyaan yang di tujukan kepada bintang tamu merupakan klarifikasi berita atas bintang tamu yang diundang. Sub maksim kuantitas mengandung maksud singkat,apa adanya. Sub maksim relevan mengandung maksud berbicara sesuai dengan topik yang diangkat pada episode itu. Sub maksim cara mengandung maksud berbicara terang sehingga mitra tutur mengerti.

Berkaitan dengan ciri wacana lisan yang dituturkan TA mempunyai beberapa ciri yang nampak(a) sering menggunakan kata-kata ekstrem atau superlatif ,seperti luar biasa,bintang tamu saya yang hebat-hebat...(b) cenderung mengulang-ulang kata , seperti saya setuju...(c) cenderung menggunakan berbagai variasi bahsa daerah(B.1), bahasa Indonesia(B2), serta bahasa asing(B3).

4. Variasi bahasa TA di acara BEM Trans 7 di lihat dari sisi tindakan (act) Teori Etnografi Komunikasi Dell Hymmes .

Tindakan (act) mencakup bentuk pesan dan isi pesan dalam peristiwa tutur di BEM, bentuk pesan yang nampak ujaran-ujaran TA dalam bahasa daerah(B.1), bahasa Indonesia(B.2), serta bahasa Inggris(B.3). Pemakaian campur bahasa 
(pidgin) disisipkan bahasa Jawa(B.1) jika bintang tamu dan atau penontonnya banyak berasal dari suku Jawa,disisipkan bahasa Inggris(B.3), jika TA ingin "bergaya" bicara bahasa Inggris. Variaisi bahasa TA sebagai tindakan nampak juga di saat menyebutkan beberapa kata filosofi dan nasihat-nasihat.

Walaupun demikian,variasi bahasa TA dari sisi tindakan(act) mudah di mengerti sebagaimana pendapat Delll Hymes dalam Alex Sobur(2009:156) pengutamaan lebih kepada tutur daripada kode, kepada fungsi daripada struktur, ada konteks ketimbang pesan.

5. Variasi bahasa TA di acara BEM Trans 7 di lihat dari sisi cara (key) Teori Etnografi Komunikasi Dell Hymmes

Variasi bahasa TA di acara BEM dikaji dari komponen tutur cara(key) merupakan tuturan yang santai ,lucu dan sinis. Tuturan lucu direspon partisipan dengan tertawa dan bersorak di ikuti tepuk tangan.Tuturan santai direspon partisipan tepuk tangan saja. Tuturan sinis direspon partisipan dengan bersorak.

Cara penyampaian tuturan dilakukan juga dengan paralinguitik seperti menaikturunkan intonasi,mencepatlambatkan kalimat yang disertai dengan gestur khasnya(idiosinkretik)

Hymmes dalam Abdul Syukur(2009:158) berpendapat suatu peristiwa tutur dan tindak tutur hendaknya dianalisis terkait dengan fungsinya, tuturan TA jika dikaji dari cara(key) lebih didominasi fungsi kontak, karena sapaan yang dilucukan atau kinesic yang dilucukan ,menciptakan peristiwa tutur tersebut lucu, santai atau sinis.

6. Variasi bahasa TA di acara BEM Trans 7 di lihat dari sisi alat,stilistik (instrument) Teori Etnografi Komunikasi Dell Hymmes

Variasi bahasa TA di acara BEM dikaji dari instrumentalities (piranti,perabotan) menggunakan saluran lisan..Bentuk tuturannya menggunakan bahasa percakapan bahasa Indonesia. Bahasa daerah menggunakan dialek bahasa jawa seperti kata;krungu,pinter,monggo. Variasi bahasa TA di acara BEM yang menggunakan dialek Jawa ,biasanya hanya bersilaba pendek.kata kata ekstrem, serta kata-kata superlatif. Bersilaba pendek contohnya monggo,pinter, Kata-kata ekstrem contohnya wong edan,syetan,kata-kata superlatif contohnya... banget.

Kenyataannya variasi bahasa TA di acara BEM menarik karena TA menguasai berbagai register bahasa percakapan dan bahasa non verbal. 
Dell Hymes dalam Alex Sobur (2009:156)menyarankan agar penutur menggunakan saluran (instrumentalities) sebagai fungsi kontekstual ,keanekaragaman fungsi dari berbagai bahasa dan alat-alat komunikasi lainnya agar proses tuturan mudah dipahami.

7. Variasi bahasa TA di acara BEM Trans 7 di lihat dari sisi norma (norms) Teori Etnografi Komunikasi Dell Hymmes.

Variasi bahasa TA di acara BEM dikaji dari norma(norms)menggunakan norma aturan orang jawa yang bekerja di Jakarta...Bentuk tuturannya pada saat menyambut bintang tamu di acara BEM menggunakan sapaan seperti ."selamat malam, apa kabar atau gimana .....”.,pada saat menyapa penonton dengan kata selamat malam...,senang berjumpa dengan anda,... Sapaan yang dituturkan oleh TA tersebut mempunyai makna akrab dan intim dan bersahabat.

Hymmes dalam Abdul Syukur(2009:158) dalam teori etnografi mengkaji sapaan mempunyai fungsi representasional (acuan pada topik),fungsi metalingualistik yaitu berfokus pada kode jika terhubung akan menciptakan pemahaman pesan yang disampaikan penutur ke mitra tutur.

8. Variasi bahasa TA di acara BEM Trans 7 di lihat dari sisi tipe tuturan( genre) Teori Etnografi Komunikasi Dell Hymme.

Variasi bahasa TA di acara BEM di kaji dari komponen tutur tipe tuturan(genre) yaitu hiburan.Variasi bahasa TA di acara BEM dikaji dari tipe tuturan(genre)menggunakan tipe tuturan hiburan reality show televisi.tipe tuturan di acara BEM banyak mengandung makna fungsi komunikasi:ekspresif,puitik. Fungsi komunikatif ekspresif terdapat di kalimat pembuka,bagian inti, kalimat penutup.dikalimat pembuka"oke,ketemu lagi di bukan empat mata" disertai raut muka TA yang semangat dan percaya diri, jenis kalimat yang dipakai eksklamatif. Contoh lainnya di bagian inti"penontonnya malam ini, bagus !". kalimat tersebut mengandung makna memuji kepada penonton . contoh lainnya,di bagian penutup"fenomenal bombastis,..." .sedangkan fungsi komunikasi puitik terdapat di tuturan ;"pucuk dicinta ulam tiba..." atau menyanyikan sebuah syair lagu,contohnya" bengawan solo...riwayatmu ini"

Hymmes dalam Abdul Syukur(2009:158)berpendapat peristiwa tutur lengkap seharusnya mengandung unsur-unsur fungsi komunikatif ekspresif,direktif(kognitif,persuasif),puitik,fungsi kontak, metalinguistik ,fungsi representasional atau acuan (tentang isi topik),fungsi kontekstual.

Kenyataannya di variasi bahasa yang di tuturkan TA di acara BEM dikaji dari sisi genre lebih dominan fungsi ekspresif dan fungsi puitik. 


\section{SIMPULAN}

Dari hasil penelitian dan pembahasan, maka dapat disimpulkan bahwa variaisi bahasa TA di acara BEM trans7 dikaji dari teori Delll Hymmes kisi S-P-E-A-K-I-N-G terdapat ciri-ciri khas TA (idiosinkretik) baik bahasa verbal maupun bahasa non verbal. Ciri khas mengandung maksud bahwa variasi bahasa tersebut tidak di gunakan orang lain/presenter lain.

Variaisi bahasa TA di acara BEM di lihat dari 8 komponen tutur setting,participant,ends,act,key ,instrumentalities,norms dan genre. Tuturan TA mengandung makna fungsi katalog lengkap Dell Hymmes dari teori etnografi komunikasi yakni fungsi komunikasi ; ekspresif, direktif(kognitif,persuasif), puitik, fungsi kontak, metalinguistik ,fungsi representasional atau acuan (tentang isi topik),fungsi kontekstual.

(a) Komponen setting: variasi bahasa yang dipakai TA hanya memenuhi unsur direktif,ekspresif dan fungsi kontak sedangkan fungsi kontekstual, puitik representasional belum nampak.

(b) Partisipan Chintia Sari(partner) seharusnya sebagai pemancing/pemarkah ternyata hanya sebagai penyela saja.bahkan, terkesan hanya menyudutkan TA .seharusnya Chintia Sari sebagai pemancing (act) dan TA berperan pelanjut (event), peranan krew musik sebagai partisipan sering hanya menjadi obyek ejekan (gaya bahasa sarkasme) oleh TA, sehingga variasi bahasa TA jika disimak tergolong kasar.Peranan penonton sebagai partisipan hanya memeriahkan peristiwa tutur saja,seperti tertawa,bersorak,merespon kata"kembali ke lap toop" dari TA.Kadang-kadang di puji(amelioratif) maupun direndahkan(peyoratif) .

(c) Variasi bahasa TA berkaitan dengan tujuan (ends) di peristiwa tutur BEN sudah di arahkan melalui tampilan di lap top.jika dalam tuturan TA tidak sesuai dengan tujuan(ends) di episode itu, TA segera mengatakan"kembali ke lap top". Kalimat"kembali ke lap top" mempunyai fungsi komunikasi direktif persuasif.interprestasi dari kalimat tersebut berarti tindak tutur yang sedang berlangsung harus tetap relevan dari tujuan (ends) yang sedang di tuturkan.Kalimat"kembali ke lap top" berarti pengontrol ,tindak tutur yang sedang berlangsung.

(d) Variasi bahasa TA dari sisi tindakan(act) mudah di mengerti sebagaimana pendapat Delll Hymes dalam Alex Sobur(2009:156) pengutamaan lebih kepada tutur daripada kode, fungsi daripada struktur, ada konteks ketimbang pesan.

(e) Tuturan TA jika dikaji dari cara (key) lebih didominasi fungsi kontak,karena sapaan yang dilucukan atau kinesic yang dilucukan ,menciptakan peristiwa tutur tersebut lucu, santai atau sinis. 
(f) Variasi bahasa TA di acara BEM menarik karena TA menguasai berbagai register bahasa percakapan dan bahasa non verbal

(g) Variasi bahasa TA di acara BEM dikaji dari norma(norms)menggunakan norma aturan orang jawa yang bekerja di Jakarta...Bentuk tuturannya pada saat menyambut bintang tamu di acara BEM menggunakan sapaan seperti ."selamat malam, apa kabar atau gimana .....".,pada saat menyapa penonton dengan kata selamat malam...,senang berjumpa dengan anda,... Sapaan yang dituturkan oleh TA tersebut mempunyai makna akrab dan intim dan bersahabat.

(h) Variasi bahasa TA di acara BEM dikaji dari tipe tuturan(genre)menggunakan tipe tuturan hiburan reality show televisi.tipe tuturan di acara BEM banyak mengandung makna fungsi komunikasi: ekspresif, puitik .

\section{IMPLEMENTASI DALAM PEMBELAJARAN BAHASA INDONESIA}

Kita harus inspiratif dalam menetukan bahan ajar bagi siswa khususnya dalam pembelajaran standar kompetensi mendengarkan memahami siaran atau cerita yang disampaikan secara langsung atau tidak langsung di kelas $X$ semester 1 SMA. Kompetensi dasar yaitu merespon siaran televisi non berita.materi pokoknya yaitu pokok-pokok isi acara dan menanggapi siaran .

Dalam pengajaran bahasa, hasil penelitian ini dapat digunakan sebagai hasil bahan pembelajaran. Sesuai kurikulum tingkat satuan pendidikan yang berlaku, para siswa dituntut untuk memliki kompetensi dalam mendengarkan dan menanggapi acara BEM yang di pandu oleh TA di lihat dari latar,bintang tamu,topik,norma dan genre . Rambu-rambu penggunaan variasi bahasa TA di Acara BEM dapat digunakan menambah wawasan bahasa percakapan, gaya bahasa dan kreatifitas gerak tubuh (gesture) sebagai bahasa non verbal yang menambah pemahaman tujuan bertutur dalam peristiwa tutur di acara BEM.

\section{SARAN-SARAN}

Saran-saran dibawah ini ditujukan pada beberapa pihak :

1) Pihak yang terkait dengan produksi dan tayangan acara BEM, terutama penulis naskah program dan pihak Trans 7 Jakarta.

a) menyusun program yang mentaati UU penyiaran No:32 tahun 2002 sehingga acara BEM dapat terus ditayangan tidak di stop oleh komisi Penyiaran Indonesia(KPI)

2) Pihak pirsawan acara BEM

a) Menyaksikan acara BEM dengan penuh bijak

b) Mendampingi putra-putrinya yang menyaksikan acara BEM

3) Pihak pendidik yang memberikan pendidikan secara kritis dalam pengajaran terutama pengajaran bahasa

a) Menambah wawasan ketrampilan berbahasa seorang presenter 
b) Menambah wawasan dalam merespon isi siaran televisi

4) Pihak peneliti lanjutan yang mempunyai perhatian pada masalah komunikasi .

a) Mengadakan penelitian dibidang kebahasaan media televisi dari sudut kajian lain.

\section{DAFTAR PUSTAKA}

Arifin, E Zaenal.2003.dasar-dasar Penulsian Karangan Ilmiah.Jakarta:Grasindo

Chaer,Abdul.dan Leonie Agustina.2004.Sosiolinguistik.Jakarta:Rineka Cipta

Depkominfo. 2000.Undang-Undang Penyiaran No:32 tahun 2002.Jakarta:Depkominfo

Effendy,Heru.2009.Industri Pertelevisian Indonesia.Jakarta: Erlangga

Gumperz, Jhon J.2003.Language and Interaction.Philadelphia:John Benyamin North America Ibrahim, Abdul Syukur.2009.Analsis Teks Wacana.Yogyakarta:Pustaka Pelajar

Keraf, Gorys. 2008. Diksi dan Gaya Bahasa.Jakarta: Gramedia

Mahsun. 2007. Metode Penelitian Bahasa.Jakarta:Rajawali Press

Mc Neill, David.2000.Language and Gesture.united Kingdom: Cambridge University

Nierenberg,I Gerald .2008.How to Read a person like a book.Yogyakarta:Qulls

Purwoko ,Heru Jati.2008.Jawa Ngoko.Jakarta:Indeks

Sobur, Alex.2009.Analisis Teks Media.Bandung:Pt Rosda Karya

Sugiyono. 2009. Metode Penelitian Kuantitatif Kualitatif dan R\& D.Bandung: alfabeta

Thompson, Neil.2003.Communication and Language.New York:Palgrave macmilan

Tim Pusat Bahasa.1990.Kamus Besar Bahasa Indonesia.Jakarta: Departemen

Pendidikan Nasional

Http:|lwww:http://en.wiktionary.org/wiki/idiosyncratic, yang diakses 26 mei 2010 